\title{
Editorial
}

\section{Lessons Regarding Percutaneous Injuries Among Healthcare Providers}

\author{
Bradley N. Doebbeling, MD, MSc
}

This issue of Infection Control and Hospital Epidemiology contains four important articles on the epidemiology and prevention of sharps or percutaneous injuries among healthcare workers. These articles as a group convincingly demonstrate the importance of a multidimensional occupational safety program within hospitals, including surveillance and data analysis, administrative and engineering control measures, consistent use of protective equipment, and safer personal work practices.

Percutaneous injuries represent one of the most common occupational injuries in hospitals, accounting for from 300,000 to 800,000 injuries per year in the United States. ${ }^{1,2}$ Percutaneous injuries are clinically important because they are the most efficient mechanism of transmission of occupational blood-borne infection. ${ }^{3}$ The occupational blood-borne pathogens of greatest concern are hepatitis $B$ virus, hepatitis $C$ virus, and human immunodeficiency virus (HIV), although other organisms may also be transmitted. ${ }^{46}$ The risk of seroconversion following a single needlestick injury from an infected source patient ranges from $5 \%$ to $35 \%$ for hepatitis B and $3 \%$ to $10 \%$ for hepatitis C and is $0.3 \%$ for HIV. $3,7,8$

A series of guidelines to better protect healthcare workers have been published and disseminated during nearly the past two decades. Universal precautions guidelines were outlined by the Centers for Disease Control in 1987, requiring workers to routinely use barrier precautions when contact with blood or certain body fluids was anticipated. ${ }^{9}$ These guidelines were updated in 1989 to include more specific recommendations, including precautions during phlebotomy. ${ }^{10}$ The Occupational Safety and Health Administration (OSHA) published its blood-borne pathogen standard in 1991, requiring institutions to train all workers at risk, provide the hepatitis $B$ vaccine, and implement and monitor compliance with universal precautions beginning in 1992. ${ }^{11}$ In 1996, the Centers for Disease Control and Prevention included universal precautions in a new prevention concept called "standard precautions."12 Standard precautions, which are designed for the care of all patients in hospitals regardless of their diagnosis or presumed infection status, now replace universal precautions. In 2000, the Needlestick Safety and Prevention Act (Public Law No. 106-430) was signed into law. Subsequently, OSHA revised its blood-borne pathogens standard to include more specific requirements regarding review and use of protective or engineered sharps injury protective devices. ${ }^{2}$ Guidelines for the management of healthcare workers exposed to blood-borne pathogens have been recently updated as well. ${ }^{13}$

Iatrogenic transmission of major blood-borne pathogens to patients following care by an infected healthcare worker has been well documented. ${ }^{4,14-16}$ As a result, guidelines for the management of healthcare workers infected with a blood-borne pathogen have been proposed. ${ }^{17,18}$

Occupational blood exposures appear to have decreased among some workers since OSHA published its blood-borne pathogen standard. This apparent decline in percutaneous injury rates has occurred as healthcare workers report increased awareness of and compliance with universal or standard precautions. Implementation of standard precautions training within hospitals has been associated with increased rates of barrier precautions use and fewer mucocutaneous blood and body fluid exposures

Dr. Doebbeling is from the Department of Internal Medicine, The University of Iowa College of Medicine; the Interdisciplinary Program in Health Care Organization, Veterans' Affairs Medical Center; and the Department of Epidemiology, The University of Iowa College of Public Health, Iowa City, Iowa.

Address reprint requests to Bradley N. Doebbeling, MD, MSc, SE $625 \mathrm{GH}$, Department of Internal Medicine, The University of Iowa College of Medicine, 200 Hawkins Drive, Iowa City, IA 52242.

The author thanks infection control professionals and hospital epidemiologists for their many contributions to his education and research. 
among nurses, physicians, and trainees. ${ }^{19,20}$ Nevertheless, occupational exposure and injury occur despite multiple published national guidelines.

The efficacy of universal or standard precautions in reducing the risk for mucocutaneous exposures has been clearly established ${ }^{20-22}$ The literature regarding the impact of universal precautions on percutaneous injury has been more limited, although universal precautions have been shown to have at least a modest effect in reducing injury rates. ${ }^{23}$ Additional evidence suggests that lack of compliance is associated with risk for percutaneous injury, at least during surgery. ${ }^{24,25}$ Unfortunately, lack of routine compliance with standard precautions is widespread and has been documented across essentially all healthcare occupations.

Increasing evidence suggests that the healthcare facility's organization and commitment to the protection of workers influences compliance with guidelines and risk of injury. For example, the institutional safety climate (or the institution's commitment to worker safety) within a hospital has been shown to be related to levels of self-reported standard precautions compliance. ${ }^{26,27}$ Both senior management support and frequent safety-related training and feedback are related to work place exposure frequency. ${ }^{28}$ Similarly, leadership support and the safety climate are important institutional predictors of the adequacy of training of workers in standard precautions. ${ }^{29}$

Organizational factors appear important in healthcare workers' risk of injury. Working in hospitals using professional nurse practice models is associated with a several-fold reduction in the risk of injury (odds ratio, 0.18 to 0.37 ) among nurses. ${ }^{30}$ Further, nurse staffing ratios and the hospital safety climate have been shown to relate to the risk of percutaneous injury. ${ }^{31,32}$ Further investigation into the role of organizational factors in influencing the effectiveness of occupational safety programs is needed. Additionally, the development of intervention studies that incorporate organizational interventions holds considerable promise.

Protective or engineered sharps injury protective devices have been strongly advocated as an approach to measurably decrease percutaneous injuries among workers. Most studies have shown a marked decrease in related types of injuries, but the results have been variable in some others. ${ }^{33,34}$ Failure to use protective devices while performing invasive procedures occurs for various reasons, including inconvenience, unavailability of the devices, interference with work, and the belief that compliance is not protective. ${ }^{35}$ Injury reductions from engineered sharps injury protective devices have varied according to the thoroughness of implementation training, perceptions of risk of percutaneous injury and blood-borne infection, and level of training and motivation to use the devices. ${ }^{36}$ Cost analyses indicate that protective devices are likely to be cost-effective long term. . $^{37,38}$

Two articles in this issue provide further convincing evidence of the role of engineered sharps injury protective devices, when incorporated as part of a comprehensive program to protect healthcare workers. ${ }^{39,40}$ However, as these studies and other research show, adequate training must be provided in the appropriate use of these devices. Even when "safer" sharps devices are made available and used, they are often not adequately activated. The multisite study by Alvarado-Ramy and colleagues convincingly demonstrates that a program including enhanced surveillance; assessment of underreporting; local selection, implementation, and evaluation of engineered sharps injury protective devices; and follow-up assessments of satisfaction, activation, and efficacy leads to a decreased risk of percutaneous injury. ${ }^{39}$ Activation of the safety features varied dramatically by site, and appeared to be influenced by extent of training, ease of use, user preference, and attitudes regarding perceived adverse events among patients. The authors suggested that involvement of healthcare workers in the selection of devices and their active involvement in training with the devices were likely to affect activation rates, adherence, and efficacy.

Mendelson et al. studied the use of safety resheathable winged steel (butterfly) needles for intravascular access. ${ }^{40}$ Using an extensive hands-on training program and implementation of the device throughout the facility, the authors demonstrated an approximate twofold reduction in the injury rate with such devices. Although the effect of this engineered sharps injury protective device on injuries did not reach significance in the prior, larger study, ${ }^{39}$ Mendelson et al. demonstrated an effect in their large referral hospital. ${ }^{40}$ Importantly, this effect was maintained during a 31-month follow-up period.

Considerable resources are necessary to effectively run a hospital epidemiology program and assist in protecting a facility's workers and patients. The Study on the Efficacy of Nosocomial Infection Control (SENIC) project suggested that one infection control professional per every 250 occupied hospital beds was one component of an effective infection control program. ${ }^{41} \mathrm{~A}$ more recent Society for Healthcare Epidemiology of America (SHEA) position paper argues that this ratio is no longer adequate because of the size and complexity of the infection control professional's workload, as well as his or her scope of practice. ${ }^{42}$ Additional data examining the resources needed to provide adequate protection of healthcare workers in hospitals are needed.

Collecting and reporting detailed surveillance data on occupational exposure is clearly a challenge, even with the additional funding provided in a research project. Gillen and colleagues found that $18 \%$ of facilities in California were willing to voluntarily provide data on percutaneous injuries. Most of the participating facilities reported no percutaneous injuries in the prior year. ${ }^{43}$ Although many of the facilities did not provide data critical for complete analyses, those reported appeared similar to results of two other large surveillance systems, the University of Virginia's Exposure Prevention Information Network and the Centers for Disease Control and Prevention's National Surveillance System for Health Care Workers. The time, expertise, and money needed for collection, management, and ongoing meaningful analysis of multi-institutional surveillance data should not be underestimated. 
Relatively little research has focused on the characteristics of training and occupational exposure across facilities. In a survey conducted in hospitals in two states during 1996 to 1997 to describe standard precautions training programs and compliance, new employee training was offered no more than twice per year by nearly one-third of the hospitals. ${ }^{44}$ Most facilities monitored the compliance of nurses, housekeepers, and laboratory technicians; physicians were rarely trained or monitored. More than half of the hospitals used needleless intravenous systems; larger hospitals used these significantly more often. Protected devices for phlebotomy or intravenous placement were purchased by only one-third of the hospitals. Percutaneous injury surveillance relied on incident reports and employee health records. Thus, healthcare institutions need to commit sufficient resources to standard precautions training and monitoring and to infection control programs to adequately meet the needs of all workers, including physicians. Additional effective interventions are needed for training employees, improving adherence, and providing needlestick prevention devices.

In an important case series in this issue, Do and colleagues from the Centers for Disease Control and Prevention describe the epidemiology of 57 healthcare workers with documented occupationally acquired HIV infection. ${ }^{45}$ Most documented cases had been occupationally exposed to blood through percutaneous injures. The timing of injuries seems similar to the epidemiology of other sharps injuries, with approximately one-third occurring during procedures, another third following procedures, and one-fifth during disposal. The locations of exposures for those with documented transmission were predominantly hospital rooms, intensive care units, and outpatient clinics, places where sharps devices are most often used. The devices most commonly associated with percutaneous injuries were hypodermic needles, one of the most frequently used sharps devices. Future reports should incorporate data from large percutaneous injury surveillance systems to allow comparisons and to put rates in perspective.

The major risk for transmission of HIV in this series was percutaneous injury. None of these percutaneous injuries were superficial, although characteristics of the injury were not available for 8 cases. Relatively few injuries resulting in HIV transmission were through two pairs of gloves, although we have no comparison data for how frequently double gloving during invasive procedures was used overall. Notably, however, $6(10 \%)$ of the cases had transmission following only mucocutaneous exposure. Relatively little data are available regarding the epidemiology of mucocutaneous exposure, as most are not reported and little research is conducted regarding such exposures. Thus, mucocutaneous exposures do carry an important risk of transmission and need to be evaluated carefully with prophylaxis considered.

Unexpected circumstances, such as sudden movements of patients or coworkers, accounted for one-fifth of the injuries. As the authors note, this finding demonstrates the need for engineering controls as well as better training and assistance of individuals performing procedures with sharps devices.

Needle recapping was previously identified as an important cause of sharps injuries. Although needle recapping still occurs, it has been a consistent part of training in the safe handling of sharps since 1987. It is reassuring that no documented cases of HIV transmission due to needle recapping have occurred since that time. Routine avoidance of needle recapping should be a cornerstone of all standard precautions training and should be continually reinforced by coworkers and supervisors.

In the study of Do et al., 14\% of the healthcare workers occupationally infected with HIV failed postexposure prophylaxis. However, only three such cases have occurred since 1996, when postexposure prophylaxis guidelines were updated to include combination antiretroviral therapy with highly active antiretroviral therapy (HAART). These recent failures were related to a multidrug-resistant isolate (one case) or to failure to take prophylaxis. Thus, postexposure prophylaxis with HAART may be particularly effective, especially in the setting of lowered viral titers in index patients receiving treatment. However, data regarding the transmission of HIV in the setting of undetectable HIV viral titers are of concern.

Percutaneous injuries do not occur at random. Yet, implementation of a comprehensive occupational health program is an effective mechanism for reducing injuries. Interventions and the introduction of sharps protective devices should be tailored to the specific occupations at risk and to the specific settings and types of devices used. The first four articles in this issue of Infection Control and Hospital Epidemiology clearly demonstrate the need for improved strategies for avoiding blood exposures. The highest level of protection of workers within healthcare settings in which sharps devices are used requires the combination of adequate training, administrative and engineering control measures, consistent use of protective equipment, and safer personal work practices. Hospital leaders need to invest in the protection of their work force.

Improved training of workers in hospitals and other healthcare settings, improved surveillance for and analysis of injury data, and routine implementation of safer needleless or engineered devices are clearly needed to protect healthcare workers. Additional well-designed research studies are needed to improve our understanding of blood exposure, injury, and underreporting among healthcare workers. Innovative intervention studies are necessary to determine how we can better protect workers in a range of healthcare settings.

This area of research has received relatively little attention from investigators and funding agencies. The research described in this issue of Infection Control and Hospital Epidemiology demonstrates that the protection of healthcare workers must be a high priority for investigators, funding agencies, and peer-reviewed journals. Only by continuing to learn from our experiences with exposure and injury in a wide range of healthcare settings will we have the opportunity to provide health care in a safe and efficient work environment. 


\section{REFERENCES}

1. Panlilio AL, Cardo DM, Campbell S, et al. Estimate of the annual number of percutaneous injuries in U.S. healthcare workers. Presented at the 4th Decennial International Conference on Nosocomial and Healthcare Associated Infections; March 5-9, 2000; Atlanta, GA.

2. Department of Labor, Occupational Safety and Health Administration. Occupational exposure to bloodborne pathogens; needlestick and other sharps injuries: final rule. Federal Register 2001;66:5318-5325.

3. Doebbeling BN. Percutaneous injury: risks and management. In Schlossberg D, ed. Current Therapy of Infectious Disease. St. Louis: Mosby-Year Book; 2000:402-407.

4. Doebbeling BN, Wenzel RP. Nosocomial viral hepatitis and infections transmitted by blood and blood products. In: Mandell GL, Bennett JE Dolin R, eds. Principles and Practice of Infectious Diseases. New York: Churchill Livingston; 1995:2616-2632.

5. Amarapurkar DN. Prevalence of hepatitis $\mathrm{C}$ antibodies in health-care workers. Lancet 1994;344:339.

6. Clever LH, LeGuyader Y. Infectious risks for health care workers. Annu Rev Public Health 1995;16;141-164.

7. Gerberding JL, Bryant-IeBlanc CE, Nelson K, et al. Risk of transmitting the human immunodeficiency virus, cytomegalovirus, and hepatitis $B$ virus to health care workers exposed to patients with AIDS and AIDSrelated complex. I Infect Dis 1987;156:1-8

8. Alter MJ. Occupational exposure to hepatitis $\mathrm{C}$ virus: a dilemma. Infect Control Hosp Epidemiol 1994;15:742-744.

9. Centers for Disease Control. Recommendations for prevention of HIV transmission in health-care settings. MMWR 1987;36:1S-18S.

10. Centers for Disease Control. Guidelines for prevention of transmission of human immunodeficiency virus and hepatitis $B$ virus to health-care and public-safety workers. MMWR 1989;38(suppl S6):1-37.

11. Department of Labor, Occupational Safety and Health Administration. Occupational exposure to bloodborne pathogens: final rule. Federal Register 1991;56:64175-64182.

12. Garner JS. Guideline for isolation precautions in hospitals. Infect Control Hosp Epidemiol 1996;17:53-80.

13. Centers for Disease Control and Prevention. Updated U.S. Public Health Service guidelines for the management of occupational exposures to $\mathrm{HBV}, \mathrm{HCV}$, and HIV and recommendations for postexposure prophylaxis. $M M W R$ 2001;50(RR-11):1-42.

14. Centers for Disease Control. Outbreak of hepatitis $B$ associated with an oral surgeon: New Hampshire. JAMA 1987;257:1709.

15. Lo B, Steinbrook R. Health care workers infected with the human immunodeficiency virus: the next steps. JAMA 1992;267:1100-1105.

16. Communicable Disease Surveillance Center. Hepatitis $C$ virus transmission from health care worker to patient. CDR Weekly 1995;5:121.

17. Gerberding J. Provider-to-patient HIV transmission: how to keep it exceedingly rare. Ann Intern Med 1999;130:64-65.

18. Gostin LO. A proposed national policy on health care workers living with HIV/AIDS and other blood-borne pathogens. JAMA 2000;284:1965-1970.

19. Fahey BJ, Koziol DE, Banks SM, Henderson DK. Frequency of nonparenteral occupational exposures to blood and body fluids before and after universal precautions training. Am J Med 1991;90:145-153.

20. Diekema DJ, Albanese MA, Schuldt SS, Doebbeling BN. Blood and body fluid exposures during clinical training: relation to universal precautions knowledge. J Gen Intern Med 1996;11:109-111.

21. Wong ES, Stotka JL, Chinchilli VM, et al. Are universal precautions effective in reducing the number of occupational exposures among health care workers? JAMA 1991;265:1123-1128.

22. Kelen GD, Green GB, Hexter DA, et al. Substantial improvement in compliance with universal precautions in an emergency department following institution of policy. Arch Intern Med 1991;151:2051-2056.

23. Beekmann SE, Vlahov D, Koziol DE, et al. Temporal association between implementation of universal precautions and a sustained, progressive decrease in percutaneous exposures to blood. Clin Infect Dis 1994; 18:562-569

24. Gerberding JL, Littell C, Brown A, et al. Risk of exposure of surgical personnel to patients' blood during surgery at San Francisco General
Hospital. N Engl J Med 1990;322:1788-1793.

25. Tokars JI, Bell DM, Culver DH, et al. Percutaneous injuries during surgical procedures. JAMA 1992;267:2899-2904.

26. Gershon RRM, Vlahov D, Felknor SA, et al. Compliance with universal precautions among health care workers at three regional hospitals. $\mathrm{Am}$ J Infect Control 1995;23:225-236.

27. Grosch JW, Gershon RRM, Murphy LR, DeJoy DM. Safety climate dimensions associated with occupational exposure to blood-borne pathogens in nurses. Am J Ind Med 1999;1 (suppl):122-124.

28. Gershon RR, Karkashian CD, Grosch JW, et al. Hospital safety climate and its relationship with safe work practices and workplace exposure incidents. Am J Infect Control 2000;28:211-221.

29. McCoy KD, Beekmann SE, Ferguson $\mathrm{KJ}$, et al. Monitoring adherence to Standard Precautions. Am J Infect Control 2001:29:24-31.

30. Aiken LH, Sloane DM, Klocinski JL. Hospital nurses' occupational exposure to blood: prospective, retrospective, and institutional reports. $A m \mathrm{~J}$ Public Health 1997:87:103-107.

31. Clarke SP, Sloane DM, Aiken LH. Effects of hospital staffing and organizational climate on needlestick injuries to nurses. Am J Public Health 2002;92:1115-1119.

32. Clarke SP, Rockett JL, Sloane DM, Aiken LH. Organizational climate, staffing, and safety equipment as predictors of needlestick injuries and near-misses in hospital nurses. Am J Infect Control 2002;30:207-216.

33. Orenstein R, Reynolds L, Karabaic M, et al. Do protective devices prevent needlestick injuries among health care workers? Am J Infect Control 1995;23:344-351.

34. L'Ecuyer PB, Schwab EO, Iademarco E, et al. Randomized prospective study of the impact of three needleless intravenous systems on needlestick injury rates. Infect Control Hosp Epidemiol 1996;17:803-808.

35. Nelsing S, Nielsen TL, Nielsen JO. Noncompliance with universal precautions and the associated risk of mucocutaneous blood exposure among Danish physicians. Infect Control Hosp Epidemiol 1997;18:692698

36. Chiarello LA, Cardo DM. Comprehensive prevention of occupational blood exposures: lessons from other countries. Infect Control Hosp Epidemiol 2000;21:562-563.

37. Laufer FN, Chiarello IA. Application of cost-effectiveness methodology to the consideration of needlestick-prevention technology. Am I Infect Control 1994;22:75-82.

38. Tan L, Hawk JC III, Sterling ML. Report of the Council on Scientific Affairs: preventing needlestick injuries in health care settings. Arch Intern Med 2001;161:929-936.

39. Alvarado-Ramy F, Beltrami EM, Short IJ, et al. A comprehensive approach to percutaneous injury prevention during phlebotomy: results of a multicenter study, 1993-1995. Infect Control Hosp Epidemiol 2003;24:97-104

40. Mendelson MH, Lin-Chen BY, Solomon R, et al. Evaluation of a safety resheathable winged steel needle for prevention of percutaneous injuries associated with intravascular-access procedures among healthcare workers. Infect Control Hosp Epidemiol 2003;24:105-112.

41. Haley RW, Culver DH, White JW, et al. The efficacy of infection surveillance and control programs in preventing nosocomial infections in US hospitals. Am J Epidemiol 1985;121:182-205.

42. Scheckler WE, Brimhall D, Buck AS, et al. Requirements for infrastructure and essential activities of infection control and epidemiology in hospitals: a consensus panel report. Infect Control Hosp Epidemiol 1998;19:114-124

43. Gillen M, McNary J, Lewis J, et al. Sharps-related injuries in California healthcare facilities: pilot study results from the Sharps Injury Surveillance Registry. Infect Control Hosp Epidemiol 2003;24:113-121.

44. Beekmann SE, Vaughn TE, McCoy KD, et al. Hospital bloodborne pathogens programs: program characteristics and blood and body fluid exposure rates. Infect Control Hosp Epidemiol 2001;22:73-82.

45. Do AN, Ciesielski CA Melter RP, Hammett TA, Li J, Fleming PI Occupationally acquired human immunodeficiency virus (HIV) infection: national case surveillance data during 20 years of the HIV epidemic in the United States. Infect Control Hosp Epidemiol 2003;24:86-96. 